\title{
The Practice and International Experience of Business Environment Construction in China
}

\author{
Yonghui CAO; He JIANG* \\ Department of Business Administration, Guangzhou College of Technology and Business, Guangzhou, 510850, China \\ *Corresponding author: He JIANG \\ E-mail: GZhappy2020@126.com
}

\begin{abstract}
In recent years, our government has done a lot of work in optimizing the business environment, and has made great progress, which has been recognized by the world. From the practice of the construction of the state-owned business environment, the central government and the State Council attach great importance to the top-level design of the construction of the business environment, issue relevant laws and regulations, and encourage the confidence of the enterprise management. Of course, while the overall business environment construction in China has made positive progress, some reforms have not yet made substantive breakthroughs. Therefore, through the analysis of the business environment report of the world bank and the comparative analysis of business environment construction at home and abroad, we can solve the obstacles and constraints in business environment, so as to enhance the international competitiveness of our government in the future business environment.
\end{abstract}

Keywords: business environment, evaluation indicators, world bank, doing business

\section{INTRODUCTION}

At present, China's economy is in the transition stage from medium and high-speed growth to high-quality development, which is also the key period to optimize the economic structure and transform the growth momentum[1]. The economic development in the new era needs a good environment to match it[2]. As an indispensable external environment for the growth of enterprises, business environment is affecting the healthy growth of market subjects, and then affecting the high-quality development of economy[3][4]. Therefore, paying attention to the construction of business environment is an important factor to ensure the sustainable growth of China's economy[5][6]. The state has carried out many reforms in recent years, hoping to further optimize the business environment through institutional innovation. In 2018, Premier Li Keqiang proposed in the government report that "optimizing the business environment is liberating productivity". It can be said that in the increasingly fierce international competition, optimizing the state-owned business environment can boost the confidence of enterprises, attract foreign investment and promote the sustainable development of the economy. In fact, the construction of business environment has become an important national strategy in China[7][8].

\section{The ranking of China's state-owned business environment construction in the world}

On October 24, 2019, the business environment project team of the world bank officially released the business environment report on the world economy, namely business environment report 2020[9]. According to the report, the score and ranking of business environment in China are higher than that in the previous year, and China has been selected by the world bank as one of the top 10 economies in the world with the greatest improvement in business environment for two consecutive years. In terms of scores, the total score of business environment in China is 77.9 , an increase of 4.26 compared with last year; in terms of global ranking of business environment, this year's ranking jumped from 46 last year to 31 this year. If we use this year's ranking to compare with the previous year's, it has been greatly improved, from 78 to 31 , up 47[12]. See Figure 1 for details:

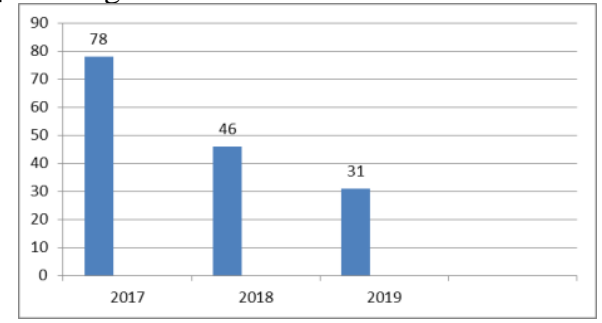

Data source: business environment report of the World Bank

Figure 1 ranking comparison of China's state-owned business environment for three consecutive years 
From the ranking and scores of the world bank, we can see that China's state-owned business environment construction has made great progress in recent years, which is also the result of our government's high attention and active efforts. According to the report, the world bank affirmed the improvement of China's business environment. As mentioned above, China ranks among the top 10 economies with the largest improvement in business environment in the world for two consecutive years. The report points out that China can achieve better results, which is the result of the Chinese government's attention and efforts to promote the reform of "deregulation services".

The World Bank report summarizes China's reform highlights, affirms China's reform achievements, and lists some specific reform measures, including: In the aspect of "setting up enterprises", the issuance of company seal is unified into one-stop service of enterprise registration, which shortens relevant procedures, time and cost. In the aspect of "building permit", the government simplified the permit requirements of low-risk building construction and saved the access time of water supply and drainage in building construction. In terms of "access to electricity", the government streamlines the process of power connection, and the electricity fee is transparent and clear. From the perspective of "protecting small and medium-sized investors", the government makes clear the ownership structure, effectively protects small and medium-sized investors, and explicitly requires the controlling shareholders to bear joint and several liability for unfair related party transactions. From the aspect of "tax payment", the government provides tax preference, reduces the tax rate of some industries and strengthens the electronic tax system; From the perspective of "cross-border trade", the government simplified the import and export procedures and improved the declaration time, port hardware facilities, customs administration and charging standards. In terms of "contract execution", the government improves the convenience of contract execution from the number of contract extension. From the perspective of "bankruptcy handling", the government has stipulated the priority rules of creditor's rights after the commencement of bankruptcy proceedings.

In general, due to various efforts made in the construction of business environment, the scores of various indicators of state-owned business environment have been improved. Compared with the 10 evaluation indicators of business environment, the world bank points out that China's ranking in the eight indicators this year has been improved. Compared with the seven indicators that improved better last year, China's ranking has increased by one this year. Specifically, in terms of the ranking of "start-up enterprise" and "execution contract", the ranking of "start-up enterprise" and "execution contract" is increased by one place compared with last year, among which "start-up enterprise" is ranked 27th and "execution contract" is ranked 5th. In terms of the index of "contract execution", China is at the forefront in this respect, because the recent reform of China has guaranteed the efficiency of contract execution. From the perspective of the time-consuming of business dispute resolution, the average time-consuming of China in this area is 496 days, better than the regional average level; the "access to electricity" index, which is 2 places higher than last year, ranks 12th. Compared with other economies in the region, Chinese enterprises only spend half of the average days of the region in terms of power connection time, China takes 32 days, and the region takes 63 days on average; the ranking of "cross-border trade" and "tax payment" indexes increased by 9 places compared with last year, among which "cross-border trade" ranked 56th and "tax payment" ranked 105th; "Handle bankruptcy" index rose 10 places, ranking 51st; The indicators with a larger improvement range are "construction permit application" and "protection of small and medium-sized investors". Among them, "construction permit application" is in the 33rd place, which is 88 places higher than last year's ranking. It is the largest improvement of 10 indicators in China this year, which has improved the overall ranking of the state-owned business environment. In China, it takes 111 days to apply for construction permit, which is 132 days lower than that in East Asia. In addition, the "protect small and medium-sized investors" index has also improved significantly, rising 36 places, ranking 28th in the world. Compared with the regional average ranking (99 places) and the OECD high-income group average ranking (46 places), it is in an advantageous position.

\section{ANALYSIS AND EXPERIENCE OF BUSINESS ENVIRONMENT AT HOME AND ABROAD}

\section{1 docking international evaluation indicators}

The positive effect of optimizing business environment on economic development has been generally recognized by many countries in the world. In recent years, China has also been making great efforts to create a good business environment, so as to promote the high-quality development of regional economy. Looking at the world and benchmarking the international market has become an important way for China to improve and optimize its business environment. Taking evaluation as a means, taking advanced as a guide, taking problems as a guide, learning from experience, avoiding risks and solving problems will help China to further optimize the market-oriented, legal and international business environment.

For the evaluation of business environment, there are several quantitative index systems in the world. According to the statistics of the global index system of government governance by the Economist magazine, there are more than 150 kinds of governance evaluation indexes with different themes, and the indexes with economic development as the theme occupy the mainstream, more than 50 kinds, among which the most influential one is the business environment report issued by the world bank every year. The report focuses on more than ten indicators 
involved in business operation, measures 190 economies, and conducts comprehensive ranking and sub ranking as a business evaluation standard that can be compared horizontally. As far as the current situation is concerned, each country attaches more importance to the research report than before. Many countries use the research results of the report as a guide to the construction of the state-owned business environment. The Chinese government pays more attention to the total score, sub scores, comprehensive ranking and sub ranking in the business environment report, and through horizontal and vertical comparison, improves the level of business environment in China. In fact, through benchmarking the advanced and making up for the short board, China's state-owned business environment construction has made great progress. In 2019, it reached the best level in China and ranked 31 st in the world.

\section{2 business environment experience}

Through the comparison of domestic and international perspectives, we can be sure that China's state-owned business environment has made remarkable achievements in recent years, and some indicators are in the forefront of all economies in the world. However, we need to be aware that there is still a certain distance between the index ranking of China's state-owned business environmental convenience and the world ranking of China's second largest economy, which lags behind most developed countries, even some developing countries. Through the business environment report, it can be found that some countries have unique experience in business environment construction, and some countries even have a substantial improvement. Therefore, we should take the report as the key point, combine the reality of our country and look at the world. First of all, it summarizes some successful models of optimizing business environment in some countries and parts of China; secondly, it analyzes and draws lessons from the experiences and practices of Russia, India and Singapore to improve the convenience of optimizing business environment in China.

\section{(1) Business environment model for reference}

First, the rule of law priority model in Singapore. For many years in a row, the world bank's business environment report ranked Singapore's business environment construction in the top three of all economies in the world, which is also an affirmation of Singapore's business environment work. Among them, the most commendable thing is Singapore's legal system. Singapore attaches great importance to system construction, with a relatively complete commercial system and a fair judicial system. This provides strong institutional support for the protection of intellectual property rights, the protection of the interests of small and medium-sized investors, and the attraction of talents in the market economy. According to the IMD world competitiveness report, Singapore's intellectual property protection system is the most sound and has done the best in the world, such as the Patent Act, the Trademark Act, the registered trademark design act and the copyright act. In addition, the competition act also protects and promotes the healthy development of the market, standardizes the market competition behavior, and provides legal guarantee for the enterprise operation.

Second, Hong Kong's international priority model. Hong Kong has an international and open environment, which provides a high standard international arena for business investment, economic and trade exchanges and cultural exchanges around the world. In the annual business environment report, Hong Kong always ranks first in terms of comprehensive ranking. This benefits from Hong Kong's international business environment. First of all, Hong Kong has a convenient international financial service industry. Banks around the world have set up corresponding offices in Hong Kong. High level financial talents ensure the continued prosperity of Hong Kong's financial industry. Secondly, there are many consulates around the world, convenient world routes, advanced international level of higher education, good cultural atmosphere, etc., which make the level of internationalization of Hong Kong far ahead of the rest of the world. Finally, the level of urban hardware facilities in Hong Kong is relatively high, and municipal engineering, urban management, transportation services and so on have laid a good foundation for the construction of international business environment in Hong Kong.

Third, the efficiency priority model of Shenzhen. Shenzhen is one of the earliest coastal open cities in China, and it is also a model city for China's reform and opening up. In the process of high-quality economic development in Shenzhen, the local government focuses on "efficiency" in the construction of business environment. From the perspective of government process, the government optimized and shortened the process, improved the efficiency of examination and approval, and provided convenient commercial services for the operation and development of enterprises through resource integration as early as a few years ago. With regard to the examination and approval of multiple departments, the government has strengthened the business coordination among units, established the linkage mechanism of examination and approval business, and greatly improved the speed of government affairs. In addition, Shenzhen took the lead in setting up an Internet + government service platform in some service centers. Some business affairs can be completed only once. Because of the concept and practice of focusing on efficiency and service, the construction of business environment in Shenzhen has a leading position in China.

(2) The example of BRICs: the experience of Russia and India

Judging from the business environment construction of 190 world economies, the business convenience ranking of Russia and India has grown rapidly in recent years. From the BRICs ranking, Russia ranks 28th in the world in terms of business environment in 2019 and first in the BRICs. If compared with the ranking of world business environment convenience of Russia in 2012, Russia has made rapid development and remarkable achievements in business environment construction. In 2012, Russia ranked 120th in 
the world. It took seven years to reach 28 th place. As a strong BRICs country, India has made great progress in the ranking of business environment in recent years. Therefore, it is beneficial for China to further optimize its business environment construction to learn from the experience of Russia and India in the same BRICs.

First, we should attach importance to the construction of business environment and carry out a number of institutional reforms in parallel. In recent years, Russia and India attach great importance to the construction of business environment, and take the system reform of optimizing business environment as an important matter of the government. Since Putin took office as president of Russia in 2012, he has issued policies on the long-term economic development of the country. In the policy, it is specially proposed to take various reform measures to optimize the business environment, aiming to substantially improve the ranking of business convenience in the world, and to put forward the quantitative target at that time, that is, from 120 in that year to 20 in 2018. At present, although it fails to reach the original goal, the world ranking has been greatly improved, which is also shocking to the world. In recent years, Russia has carried out 23 specific reforms. Through the business environment report of the world bank, it can be found that Russia has made outstanding achievements in enterprise start-up services, construction license acquisition, tax reform, government supervision, etc. From the perspective of India, after Prime Minister Modi took office in 2014, he set a plan to improve the world ranking of business facilitation, and expected to reach the goal of top 50 in the world by 2022 . During the reform, the Indian government put forward a number of specific reform programs, such as business start-up, construction license, goods and services tax, and put forward the "made in India" national strategy to effectively improve the construction of business environment.

Second, set up environmental assessment indicators and carry out environmental assessment effectively. In order to promote the improvement of business environment, the Russian government has formulated 45 evaluation index systems in four key areas, including business system reform, infrastructure and resources, regulatory environment, and support of small and medium-sized enterprises, according to the evaluation standards of the world bank and the specific national conditions of Russia. In order to carry out evaluation and improvement, a strategic initiative agency was set up, which is responsible for the evaluation of the Russian Federal Administrative Region, so as to promote the construction of business environment. The government of India, through the Bureau of industrial policy promotion, evaluated the business environment of its various administrative regions, and in 2017, formulated the business environment reform action plan, namely the BrAC plan. The plan aims to carry out reforms in 12 major areas and puts forward more than 300 reform measures and suggestions. At the same time, the Industrial Policy Promotion Bureau tracks the rectification of reform measures, and publishes results and compares rankings.
Third, the business environment should be included in the assessment to encourage local in-depth reform. In order to effectively improve the business environment reform, the Russian government, which takes the improvement of business environment as the key work of the government, has adjusted the performance assessment indicators of local government leaders since 2017, and has taken the improvement of business environment of local government as an important examination content. India also regards the change of business environment indicators as an important evaluation factor of whether local governments have good performance, so as to stimulate local governments to further reform and improve the competitiveness of business environment.

\section{CONCLUSION}

To sum up, by analyzing the development of China's state-owned business environment in recent years, we can be sure that our government has done a lot of work in optimizing the business environment and made great progress, which has been recognized by the world. Especially in the past three years, China's central government and the State Council have attached great importance to the top-level design of business environment construction, introduced relevant laws and regulations, and encouraged the confidence of enterprise management. In particular, the regulations on the optimization of business environment issued in 2019 has raised the construction of business environment to a legislative level, which shows the determination of our government to this work. Of course, while China's overall business environment construction has made positive progress, some reforms have not yet made substantive breakthroughs. Therefore, it is urgent to carry out in-depth reforms, compared with the advanced ones, and to reflect on ourselves in order to break the barriers and constraints in business environment, so as to improve the international competitiveness of China's Government in business environment in the future.

\section{ACKNOWLEDGMENT}

This work was financially Sponsored by The 13th five year plan of Education Science in Guangdong Province, 2019 University Philosophy and Social Sciences special research project, the research area of one belt, one road and one big area in Guangdong Bay, Hong Kong and Macao, Serial number 21.

\section{REFERENCES}

[1] Wei Xiahai, Dong Zhiqiang, Zhang Yongjing. Why is the business environment so important?-Empirical Evidence from "internal and external hustle and bustle" of private entrepreneurs $[\mathrm{J}]$. Economic science, 2015 (2): 105-116 
[2] Hamilton L, Webster P. The international business environment[M]. Oxford University Press, 2018.

[3] Bitzenis A, Nito E. Obstacles to entrepreneurship in a transition business environment: the case of Albania[J]. Journal of small business and enterprise development, 2005, 12(4): 564-578.

[4] Gecevska V, Chiabert P, Anisic Z, et al. Product lifecycle management through innovative and competitive business environment[J]. Journal of Industrial Engineering and Management, 2010, 3(2): 323-336.

[5] Bao Xiaoye, Liu Jianghui, Huang Guoyan. Reflections on further optimizing the business environment in Shanghai-Based on the world bank business environment assessment report [J]. Shanghai business, 2019 (1): 2

[6] Huang Zexuan. The construction framework and implementation path of the rule of law for the optimization of business environment in Guangxi [J]. Journal of Guangxi University for Nationalities (PHILOSOPHY AND SOCIAL SCIENCES EDITION), 2019 (5): 29

[7] Jiang Jing. System, business environment and service industry development-Evidence from the World Bank's global business environment report [J]. Xuehai, 2017 (January 2017): 176-183

[8] Liu Shuman. Considerations on the rule of law to further optimize business environment [J]. People's forum, 2019 (19): 44

[9] Doing business group of the World Bank. Doing Business 2020. https://chinese.doingbusiness.org/ 